verbraud auf ber $2500=\mathrm{km}=$ Streffe beträgt Demmadi $880 \mathrm{~kg}$. Die Butchenbrennfol $\mathfrak{z}_{z}$.

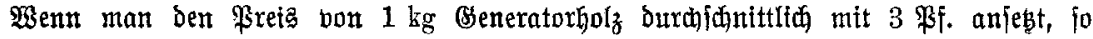

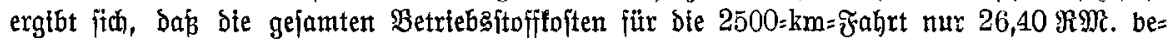

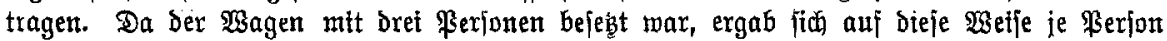

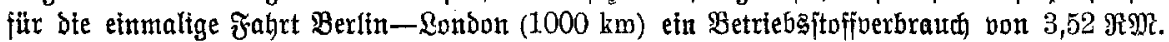

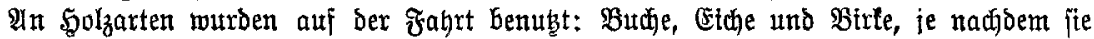

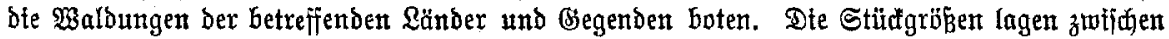

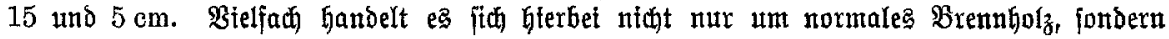

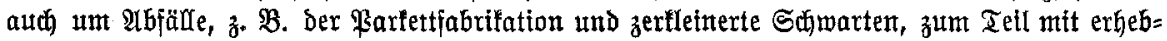

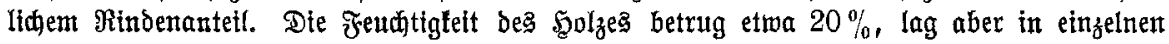
Făllen auc nennensimert Darüber.

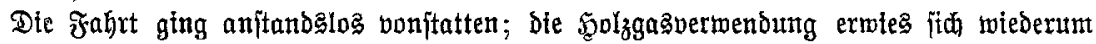

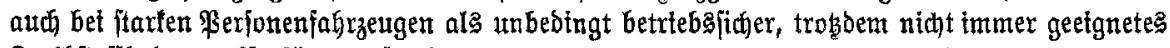
Dreibitoifholz zur ßerjügung jtond.

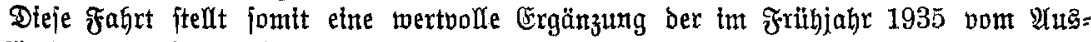

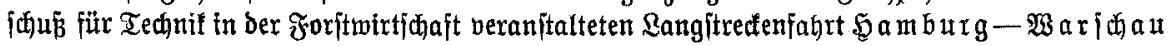

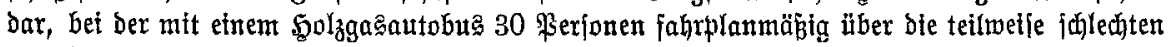

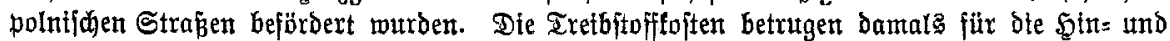

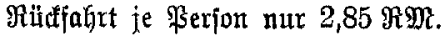

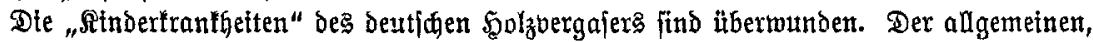

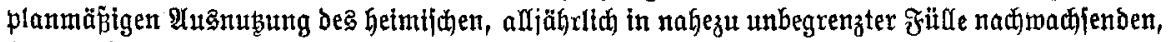

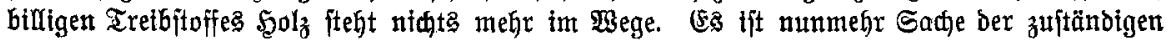

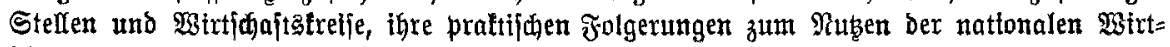
fithajt $z^{\mathfrak{t}}$ z

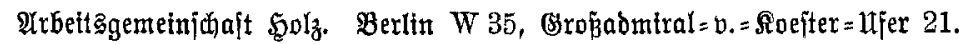

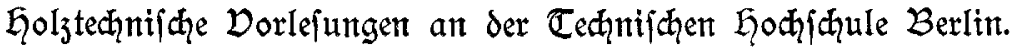

Waie in frïheren Semejtern, findet aud in biejem Semejter wteder ein Borlejung von Forftmeifter Dr. v. Monroy Berlin, an ber Tedjnijden Sodfdhule, Berlin=(E) arlottenfurg, jtatt über

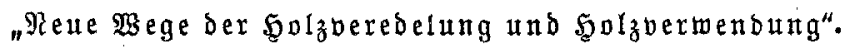

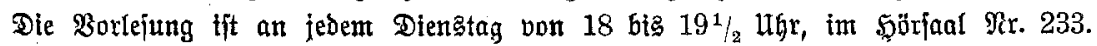
Die Betelligung ift aud für Michtjtubterende möglict.

A. I. $\mathfrak{~}$.

\section{Prüfung von Geräten für das Aufladen von Ģolj.}

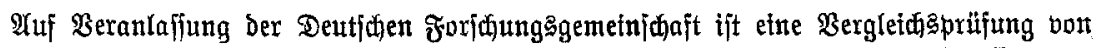

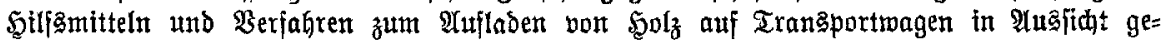
nommen. Diefe Frage ijt Deshalb widitig, weil gerabe bei Rangholz ble Tranaporttojten

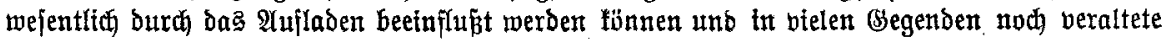

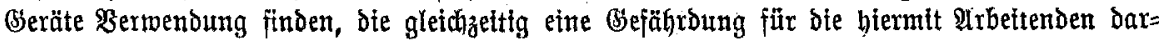
ftellen. Es wito baher gebeten, Erfafinungen auf biejem Bebiet, bie żt einer Berbefjerung

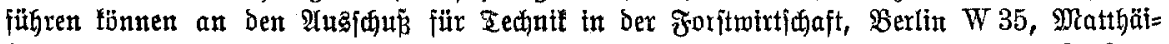
firchplate 8 , einzureidjen.

भ. $\mathfrak{i}$ ₹. 